\title{
Some experiments on supply of ions to the absorbing root surface
}

\author{
L. K. Wiersum
}

Institute for Soil Fertility, Haren (Gr.), the Netherlands

Accepted: 24 May 1973

\section{Summary}

By means of a simple experimental set-up the principal modes of supply of ions to the root surface of tomato plants could be illustrated with quantitative data. The importance of transpiration and of concentration in the solution for the mechanism of supply by mass-flow is illustrated. The data make it possible to calculate the necessity of additional supply by diffusion under certain conditions and its relative importance. Both the expected phenomena of either strong depletion or accumulation of ions in the solution in the rooted zone were confirmed by substrate analysis.

\section{Introduction}

The fact that application of fertilizer is so often practiced to obtain higher yields points to the fact that quite often the supply of nutrients is a growth-limiting factor. Even after dispersion throughout a smaller or larger part of the soil most ions have to be transported towards the root surface by some mechanism. The amount of soil in direct contact with even a large root mass is mostly only a minute fraction of the total soil volume involved (Wiersum, 1961) and contains an insufficient available supply.

Modern research on soil fertility now recognizes the fact that besides the amount of available nutrients in the soil, the mobility is equally important. Thus the modes of transport of the nutrient ions have to be investigated as well as the modes of exploitation of the soil by root systems (Barley, 1970). According to Barber (1962; Barber et al., 1963) one can conceive the supply of ions at the root surface to be the result of three separate processes: interception as a result of contact by continuous growth, diffusion as triggered by depletion at the root surface, and mass-flow along with the attracted water used in transpiration and growth.

A fair amount of research has already been performed in this field (Wiersum, 1962, 1969; Barber \& Ozanne, 1970; Drew \& Nye, 1970; Chevalier, 1971; Baldwin et al., 1972). Also physical models for mathematical treatment of the processes involved have heen conceived (Passioura \& Frere, 1967; Tinker, 1969), besides the more experimental approach. To extend our knowledge, however, many more quantitative data are needed.

In the experiments to be described an attempt has been made to obtain some simple information of a quantitative nature, mainly aiming at establishing some relationships between concentration in the nutrient solution as it affects the relative importance of supply by convection or diffusion. A very simple approach, in which complicating 
factors could be avoided, seemed attractive. It also allows easy manipulation and a wide range of variations. So a comparison was made of the uptake of water and nutrient ions in stirred nutrient solution and that in inert sand subirrigated with the same solution. The attempt to gather more information on the relative and actual values of flux of different ions across the root surface should also contribute to bridge the gap between information obtained by plant physiologists and that derived by soil chemists.

\section{Experimental procedure}

The basic idea was to compare the uptake of ions in a system in which there is a more or less constant concentration at the root surface, irrespective of intake of water, with a system in which replenishment of ions at the root surface is highly dependent on the consumption of water. The first condition was achieved by growing the plants in a nutrient solution well stirred by means of the air passing through it for aeration, and repplenished regularly. To achieve the second condition the tomato plants were grown in a vessel mainly filled with washed coarse sand. This sand was continuously moistened by capillary rise of the solution, maintained at a fixed free level. In this sub-irrigation system there is no movement of water, except that induced by the transpiring plant. The supply of ions to the rooted zone is thus very strongly linked to the movement of water, although diffution processes may occur in the vicinity of the root surface.

In Fig. 1 the details of the setup are given. The air used for aerating and stirring the nutrient solution in vessel $A$ is moistened in bottel $B$ to prevent evaporation from the nutrient solution as much as possible. The bottle $\mathrm{C}$ is used to collect the remaining

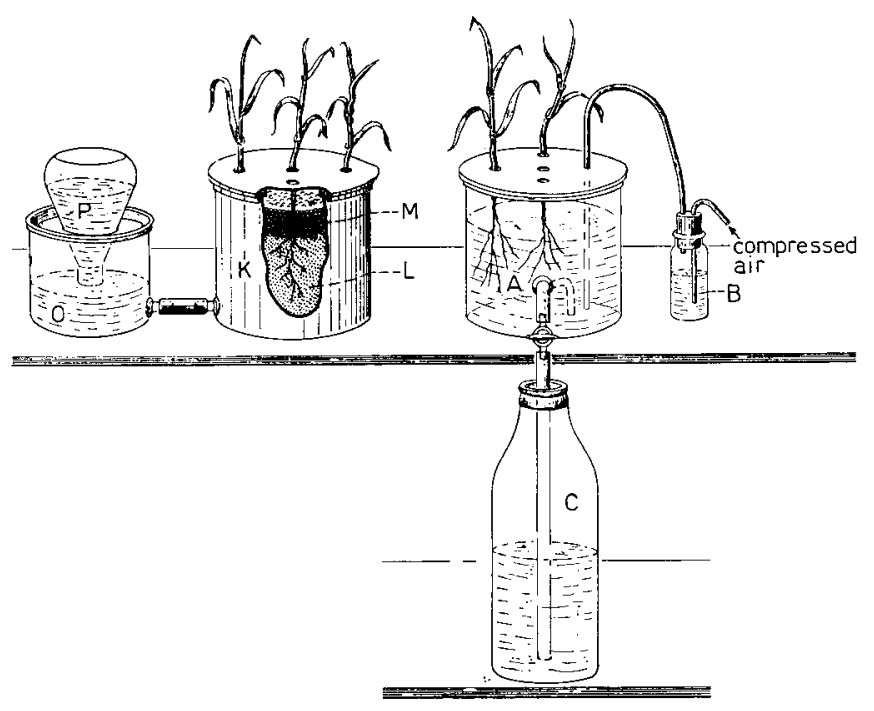

Fig.1. Schematic diagram of the experimental set-up.

$\mathrm{A}=$ vessel with aerated and stirred nutrient solution.

$\mathrm{K}=$ vessel filled with sub-irrigated sand (L), covered with plastic heads (M). 
nutrient solution before replenishment, so that the water loss by transpiration can be calculated.

The coarse sand (L) in the vessel $K$ is covered by a layer of plastic beads $(M)$ to prevent excessive evaporation and the formation of a plant-damaging salt crust at the surface. The vessel is joined to a constant-level system consisting of the inverted flask $(\mathrm{P})$ in the plastic box $(\mathrm{O})$. Water consumption is measured by repeated weighing of the system. Blanks, without plant, are run in both systems to assess evaporation.

Our facilities have recently been improved, so that the experiments can now be performed under constant conditions of artificial lighting and temperature, although humidity varies. This allows a comparison of experiments - usually lasting about two months - conducted at different times. Illumination in the constant-temperature room is achieved by six Philips TLMF $60 \mathrm{~W}$ lamps, which give about 5000 lux intensity at plant level.

Under these conditions comparisons can be made between the effects of different compositions and concentrations of the nutrient solution. Ambient temperature can be varied and it is also possible to alter transpiration by bagging the plants or by utilizing extra ventilation.

The uptake of water by the plants is recorded by weighing the transpirational loss occurring between replenishments. The uptake of ions is derived from analysis of both the plant tops and the roots. Both fresh and dry weight of the plants are recorded.

In presenting the data the rate of uptake is expressed in relative values. A rate of entry of 100 denotes that along with a consumption of 1 litre of water the same amount of ions is absorbed as this volume of solution contains. This presentation makes it easy to interpret the effects of mass-flow in the sub-irrigated system.

Another way of presenting the results is to calculate the percentage of the total supply utilized by the plant. In the solution culture the supply is the amount of nutrient contained in the total volume of solution used in the replenishments. In the sub-irrigated sand culture the total amount of ions at the plants disposal is the amount of minerals contained in the transpired amount of water plus the amount of water contained in the sand substrate at the beginning, as this is largely permeated by roots. It is considered that the latter amount could be transported to the root surface by means of diffusion.

\section{Results and discussion}

First of all a comparison can be made between a series of experiments conducted under more or less the same conditions but in which the concentration of some elements in the nutrient solution were varied. In Table 1 the results with three compositions of the solution are summarized.

The data clearly demonstrate that lowering of the concentration of a nutrient in the solution results in a higher relative rate of uptake. The very high relative rate of uptake of $\mathrm{N}$ in Experiment B2 suggests a very high demand. This is corroborated by the fact that the plants have a somewhat lower $\mathrm{N}$ content $(4.4 \%)$ as compared to 5.0 and $5.0 \%$ in the tomatoes of Experiment $\mathrm{A} 1$ and $\mathrm{C} 1$. These phenomena are repeated in the behaviour of $\mathrm{Ca}$, where again the higher relative intake rate in Experiment $\mathrm{B} 2$ is related to the lowest content ( $1.9 \%$ versus $3.0 \%$ in $\mathrm{A} 2$ and $2.7 \%$ in $\mathrm{C} 1$ ).

Another comparison can be made among plants in an experiment where transpiration has been varied. The results are presented in Table 2 . Restriction of the transpiration 
Table 1. The relative influx rate of nutrient ions and plant contents in relation to their concentrations in the water culture experiments with tomatoes.

\begin{tabular}{|c|c|c|c|c|c|c|c|c|c|c|c|c|c|c|}
\hline \multirow[t]{4}{*}{ Exp. } & \multicolumn{4}{|c|}{ Concentration $(\mathrm{mg} / \mathrm{l})$} & \multirow{4}{*}{$\begin{array}{l}\text { Fresh } \\
\text { weight } \\
\text { (g) }\end{array}$} & \multirow{4}{*}{$\begin{array}{l}\text { Transpi- } \\
\text { ration } \\
\left(\mathrm{cm}^{3 /} /\right. \\
\text { plant })\end{array}$} & \multirow{2}{*}{\multicolumn{8}{|c|}{$\begin{array}{l}\text { Relative influx rate } \\
\text { of the plants }\end{array}$}} \\
\hline & \multirow{3}{*}{$\mathbf{N}$} & \multirow{3}{*}{$\mathbf{P}$} & \multirow{3}{*}{$\mathbf{K}$} & \multirow{3}{*}{$\mathrm{Ca}$} & & & & & & & & & & \\
\hline & & & & & & & \multicolumn{2}{|l|}{$\overline{\mathbf{N}}$} & \multicolumn{2}{|l|}{$\mathbf{P}$} & \multicolumn{2}{|l|}{$\mathbf{K}$} & \multicolumn{2}{|l|}{$\mathrm{Ca}$} \\
\hline & & & & & & & flux & $\%$ & flux & $\%$ & flux & $\%$ & fiux & $\%$ \\
\hline $\mathrm{B} 2$ & 48 & 15 & 140 & 40 & 112 & 3699 & 252 & 4.4 & 87 & 0.5 & 63 & 3.2 & 134 & 1.9 \\
\hline A1 & 83 & 15 & 140 & 90 & 204 & 5455 & 174 & 5.0 & 73 & 0.4 & 70 & 3.4 & 94 & 3.0 \\
\hline $\mathrm{C} 1$ & 103 & 15 & 197 & 90 & 211 & 4924 & 151 & 5.0 & 85 & 0.4 & 57 & 3.5 & 95 & 2.7 \\
\hline
\end{tabular}

Table 2. The relative ion influx rate and plant weight of tomato plants in relation to transpiration in the water culture experiments.

\begin{tabular}{|c|c|c|c|c|c|c|c|c|c|c|c|}
\hline \multirow[t]{2}{*}{ Exp. } & \multicolumn{4}{|c|}{ Concentration $(\mathrm{mg} / \mathrm{l})$} & \multirow[t]{2}{*}{ Air } & \multirow{2}{*}{$\begin{array}{l}\text { Transpi- } \\
\text { ration } \\
\left(\mathrm{cm}^{3} / \text { plant }\right)\end{array}$} & \multirow{2}{*}{$\begin{array}{l}\text { Plant } \\
\text { weight } \\
\text { (g dry) }\end{array}$} & \multicolumn{4}{|c|}{ Relative influx rate } \\
\hline & $\mathbf{N}$ & $\mathbf{P}$ & $\mathrm{K}$ & $\mathrm{Ca}$ & & & & $\mathrm{N}$ & $\mathbf{P}$ & $\mathbf{K}$ & $\mathrm{Ca}$ \\
\hline VI & 91 & 12 & 92 & 123 & $\begin{array}{l}\text { dry } \\
\text { normal } \\
\text { moist }\end{array}$ & $\begin{array}{r}1143 \\
791 \\
604\end{array}$ & $\begin{array}{l}1.65 \\
1.49 \\
1.46\end{array}$ & $\begin{array}{r}60 \\
89 \\
107\end{array}$ & $\begin{array}{r}90 \\
145 \\
157\end{array}$ & $\begin{array}{l}108 \\
154 \\
202\end{array}$ & $\begin{array}{l}33 \\
39 \\
51\end{array}$ \\
\hline
\end{tabular}

results in an increase in relative influx rate for all of the four measured elements. Plant dry weight of the tomatoes is only slightly influenced.

Both examples of results point to the fact that within a more or less normal range of conditions the plant attempts to obtain the required amount of nutrients, irrespective of the intensity of the flux of water across the root system, as long as this is not too strongly impaired. This corroborates the fact that the entry of water and that of ions occur by two essentially distinct processes.

Another implication from these data is that a relative rate of entry exceeding 100 denotes a situation where the amount of water entering the plant is too small to contain the required amount of ions, unless the concentration in solution is raised.

The importance of mass-flow in the supply of the plant is clearly borne out by the results obtained in the sub-irrigated sand cultures. The amount of nutrient supplied in this way is a function of both volume of water absorbed and of concentration. The effect of concentration is clearly evident from the results presented in Table 3. The two higher $\mathbf{N}$ concentrations gave reasonably good plants, but the lower concentration

Table 3. Effect of the nitrogen concentration of the sub-irrigated solution on the nitrogen supply by mass-flow and the plant weight in a sand culture with tomatoes.

\begin{tabular}{lcclc}
\hline Exp. & $\begin{array}{l}\mathrm{N} \\
(\mathrm{mg} / \mathrm{l})\end{array}$ & $\begin{array}{l}\text { Fresh weight } \\
(\mathrm{g})\end{array}$ & $\begin{array}{l}\text { Relative } \\
\text { influx rate }\end{array}$ & $\begin{array}{l}\% \mathrm{~N} \text { in } \\
\text { plant }\end{array}$ \\
B2 & & 8 & 173 & 3.30 \\
$\mathrm{~A} 1$ & 48 & 38 & 117 & 3.46 \\
$\mathrm{C} 1$ & 83 & 35 & 91 & 3.60 \\
\hline
\end{tabular}


Table 4. The effect of transpiration in sand-culture on potassium uptake of tomato plants

\begin{tabular}{|c|c|c|c|c|c|c|c|}
\hline \multirow[t]{2}{*}{ Exp. } & \multirow{2}{*}{$\begin{array}{l}\mathrm{K} \\
(\mathrm{mg} / \mathrm{l})\end{array}$} & \multirow[t]{2}{*}{ Air } & \multirow{2}{*}{$\begin{array}{l}\text { Transpi- } \\
\text { ration } \\
\left(\mathrm{cm}^{3} / \text { plant }\right)\end{array}$} & \multirow{2}{*}{$\begin{array}{l}\text { Dry } \\
\text { matter } \\
\text { (g) }\end{array}$} & \multirow{2}{*}{$\begin{array}{l}\text { Relative } \\
\text { influx }\end{array}$} & \multicolumn{2}{|l|}{$\mathrm{K}$} \\
\hline & & & & & & $\begin{array}{l}\text { content } \\
(\%)\end{array}$ & $\begin{array}{l}\text { absorl hed } \\
\text { ( } \mathrm{mg})\end{array}$ \\
\hline V & 92 & $\begin{array}{l}\text { dry } \\
\text { moist }\end{array}$ & $\begin{array}{r}1233 \\
867\end{array}$ & $\begin{array}{l}1.8 \\
1.7\end{array}$ & $\begin{array}{l}102 \\
143\end{array}$ & $\begin{array}{l}6.5 \\
5.6\end{array}$ & $\begin{array}{r}116 \\
92\end{array}$ \\
\hline
\end{tabular}

Table 5. Relative influx rates (I) and percentages utilization of the total supply of $\mathrm{N}, \mathrm{P}$ and $\mathrm{K}$ (II) in sand and solution cultures with tomato plants.

\begin{tabular}{|c|c|c|c|c|c|c|c|c|c|c|c|}
\hline \multirow[t]{3}{*}{ Exp. } & \multirow{2}{*}{\multicolumn{3}{|c|}{$\begin{array}{l}\text { Concentration } \\
(\mathrm{mg} / \mathrm{l})\end{array}$}} & \multirow[t]{3}{*}{ Weight } & \multirow{3}{*}{$\begin{array}{l}\text { Transp. } \\
\left(\mathrm{cm}^{3} /\right. \\
\text { plant })\end{array}$} & \multicolumn{2}{|l|}{$\mathbf{N}$} & \multicolumn{2}{|l|}{$P$} & \multicolumn{2}{|l|}{$\mathbf{K}$} \\
\hline & & & & & & I & II & I & II & I & II \\
\hline & $\mathbf{N}$ & $\mathbf{P}$ & $\mathrm{K}$ & & & & & & & & \\
\hline \multirow{2}{*}{$\begin{array}{l}\text { B2 sol. } \\
\text { sand }\end{array}$} & 48 & 15 & 140 & $112 \mathrm{~g}$ fresh & 3699 & 252 & 61 & 87 & 21 & 63 & 15 \\
\hline & 48 & 15 & 140 & $8 \mathrm{~g}$ fresh & 547 & 173 & 104 & 36 & 22 & 46 & 27 \\
\hline \multirow{2}{*}{$\begin{array}{l}\text { IV sol. } \\
\text { sand }\end{array}$} & 91 & 12 & 92 & $2.62 \mathrm{~g}$ dry & 1260 & 95 & 11 & 157 & 18 & 208 & 24 \\
\hline & 91 & 12 & 92 & $2.89 \mathrm{~g} \mathrm{dry}$ & 1244 & 97 & 76 & 114 & 89 & 135 & 105 \\
\hline
\end{tabular}

of $48 \mathrm{mg} / 1$ resulted in small starved plants, containing less nitrogen. This low concentration resulted in an insufficient amount of $\mathrm{N}$ transported to the plant, although the substrate had been completely utilized (compare Table 5).

By manipulation of the transpiration, the mass-flow supply is also affected as is demonstrated by the results presented in Table 4. Although growth of the plants is still only slightly restricted, the amount of $K$ absorbed and the $K$ content of the plant are definitely lowered in the moist atmosphere, as insufficient solution is drawn into the rooted sand $(\mathrm{L})$.

In both examples, the calculated relative rate of entry of $\mathrm{N}$ or $\mathrm{K}$ rises far above 100 when the supply by mass-flow has failed.

If the plant contains a higher content of an ion than could have been supplied by mass-flow, an additional process must have occurred. This additional supply can only be due to diffusion from the amount dissolved in the mass of solution contained in the sand and thus sufficiently near to the roots. If this additional supply by diffusion occurs, the percentage of utilization of the total amount supplied may rise to high values, ultimately reaching $100 \%$.

Table 6. Mineral content of the nutrient solution in the sandsubstrate at the end of an experiment.

\begin{tabular}{lrrrr}
\hline & \multicolumn{4}{c}{ Contents $(\mathrm{mg} / \mathrm{l})$} \\
\cline { 2 - 5 } & $\mathrm{N}$ & $\mathrm{N}$ & $\mathrm{K}$ & $\mathrm{Ca}$ \\
Original solution in the sand: & 80 & $48(\mathrm{~B} 2)$ & 140 & 90 \\
rooted zone & 6 & 6 & 270 & 245 \\
zone devoid of roots & 29 & - & - & 220 \\
\hline
\end{tabular}


That this is indeed the case is demonstrated by the results given in Table 5 . In Experiment B2 (sand) the low $\mathrm{N}$ content of the solution induces this phenomenon, and in Experiment IV the $\mathrm{K}$ an $\mathrm{P}$ ions are in a critical concentration range. That the calculated values for total utilization rise above 100 must be ascribed to small inaccuracies in measurements and analysis. This more or less complete utilization of the nutrient in the water remaining in the sand at the end of the experiment is confirmed by analysis of the moist sand (Table 6). The low $\mathrm{N}$ contents measured in the sand can be related to the high total $\mathrm{N}$ utilization (calculated as $104 \%$ ) for Experiment B2 in Table 5 .

If the relative rate of intake is low, however, even in sand culture, this should result in a larger supply than the amount absorbed. The result should be an accumulation in the rooted region. Also this phenomenon could be confirmed by extraction of the substrate. The data given in Table 6 for $\mathrm{K}$ and $\mathrm{Ca}$ may be related to values of relative rate of influx for Experiment $\mathrm{B} 2$ as regards $\mathrm{K}$ (Table 5), and the general low influx rates for $\mathrm{Ca}$ in these sand cultures (Table 2).

\section{References}

Baldwin, J. P., P. B. Tinker \& P. H. Nye, 1972. Uptake of solutes by multiple root systems from soil. II. Pl. Soil 36: 693-708.

Barber, S. A., 1962. A diffusion and mass-flow concept of soil nutrient availability. Soil Sci. 93: $39-49$.

Barber, S. A. \& P. G. Ozanne, 1970. Autoradiographic evidence for the differential effect of four plant species in altering the calcium content of the rhizosphere soil. Proc. Soil Sci. Soc. Am. 34: 635-637.

Barber, S. A., J, M. Walker \& E. H. Vasey, 1963. Mechanisms for the movement of plant nutrients from the soil and fertilizer to the plant root. Agric. Fd Chem. 11: 204-207.

Barley, K .P., 1970. The configuration of the root system in relation to nutrient uptake. Adv. Agron. 22: $159-201$.

Chevalier, M., 1971. Principal aspects of the potassium nutrition of plants. Potash. Rev., Subject 16, 53 ith suite.

Drew, M. C. \& P. H. Nye, 1970. The supply of nutrient ions by diffusion to plant roots in soil. III. Uptake of phosphate of onion, leek, and ryegrass. Pl. Soil 33: 545-563.

Passioura, J. B. \& M. H. Frere, 1967. Numerical analysis of the convection and diffusion of solutes to roots. Austr. J. Soil Res. 5: 149-159.

Tinkler, P. B., 1969. The transport of ions in the soil around plant roots. In: I. H. Rorison, Ecological aspects of the mineral nutrition of plants, p. 135-147. Blackwell, Oxford and Edinburgh.

Wiersum, L. K., 1961. Utilization of soil by the plant root system. Pl. Soil 15: 189-192.

Wiersum, L. K., 1962. Uptake of nitrogen and phosphorus in relation to soil structure and nutrient mobility. Pl. Soil 16: 62-71.

Wiersum, L. K., 1969. Soil water content in relation to nutrient uptake by the plant. Versl. Meded. Comm. hydrol. Onderz. T.N.O. 15: 74-89. 